\title{
THE DETERMINATION OF AN APPROPRIATE URBAN PRODUCTION FUNCTION: A STATISTICAL APPROACH
}

\author{
Neal E. Duffy*
}

\section{Introduction}

Since 1973 there have been several attempts to apply microeconomic production functions to urban areas. The object of these studies has usually been to determine the degree of returns to scale in city size, or productivity differences between small and large cities. The importance of the issue is that if scale economies are present it would be desirable to attain a size distribution more heavily weighted with larger cities. Up to now the range of production functions estimated has been somewhat limited and has been based mostly on data availability or computational ease. The contribution of this paper is to use a more rigorous statistical approach to determine if a most appropriate empirical urban production function exists. The range of production functions is much more inclusive than those previously estimated by others, owing to the use of a new series of urban capital stock estimates.

\section{Background}

Economists have long been aware of the theoretical benefits of larger cities. Several authors, including Goldstein and Gronberg (1984), Garofalo and Fogarty (1983), Alperovich (1982), Yezer and Goldfarb (1978), and Henderson (1974), have attempted to establish an analytical framework for 'agglomeration economies.' Part of the reason for the current interest is that cross section production function studies have often run into difficulty because of the uneven distribution of agglomerative forces across states. For example, Lande (1978), who estimated manufacturing production functions using cross section

\footnotetext{
*Assistant Professor of Economics, School of Business and Economics, State University of New York at Plattsburgh. The author wishes to thank three anonymous referees for their helpful comments on an earlier draft, and also Michael S. Fogarty and Gasper A. Garofalo of the Federal Reserve Bank, Cleveland and University of Akron, respectively, for the use of their urban capital stock estimates.
}

state data, concluded that "the appropriate unit of analysis is the urban area (SMSA) rather than the state" because of the erratic results he obtained. Nicholson, also using state data, showed this more explicitly by using urban dummy variables to capture the differential effects of agglomeration in each state. These effects turned out to be both positive and significant.

Theoretical justification for the existence of urban agglomeration effects was long ago established by Hoover (1948) and Isard (1956), and more recently by Richardson (1973). They suggested that agglomerative efficiency advantages could be explained by scale economies related to size of city (urbanization economies), size of industry (localization economies), and/or size of firm (internal returns to scale). Single equation production functions have often been used to estimate these scale economies, frequently without any attempt to isolate their source. At the minimum, the estimates are usually then subjected to hypothesis tests, indicating whether constant returns to scale (RTS) should be accepted or rejected. Though such aggregate production functions have often been criticized for their theoretical deficiencies, they have nevertheless been widely accepted as an empirical tool which can provide useful statistical information.

Although specific functional forms are often called for when testing specific hypotheses, nowhere in the urban literature has a particular functional form emerged as being preferable on strictly 'a priori' grounds. Yet, as stated by Dragonette (1983), it is well known that "the form of the production function, and the nature of returns to scale have important implications for the theory of investment behavior, market structure, and the concentration of industries." The form of the production function is also directly related to income distribution and technological change issues, and indirectly related to the determination of an optimum city size. In relation to the latter issue for example, Fogarty and Garofalo (1978) used a simultaneous equation model that required an urban production function to esti- 
mate their 'net' agglomeration economies.

The purpose of this paper is not to address the issues connected with urban production characteristics, nor is it to suggest any new theoretical applications. Instead, it is simply to determine if there is clear evidence in favor of a particular functional form, thus helping researchers to eliminate some of the arbitrariness involved in their selection. More importantly, it may serve to reduce the amount of bias present in certain empirical studies and may also cause urban economists to rethink some aspects of their theoretical models. In the next section, the statistical method will be outlined, and this will be followed by a brief discussion of data. Results and conclusions will then be presented in the last two sections.

\section{Method}

The empirical approach to the problem of determining an optimum urban production function is conceptually very simple: estimate as many different types of production functions as possible and then use statistical tests to find the model which "best fits the data." To meet the first objective, estimates were obtained for each of the functions listed in Table 1. Following Mizon (1977) and Leech (1975), no prior constraints were initially placed on error structure. All of the listed functions, with the possible exception of the Ringstad specification, have been thoroughly examined and sufficiently used in the literature to obviate a detailed discussion of individual properties. They can be classified into four general categories: Cobb Douglas $(1,2)$, CES $(3,4,5,6,7)$, VES $(8,9,11)$, and nonhomogeneous $(8,10,11,12)$. Several additional production functions which did not survive the estimation stage due to computational difficulties are not reported here. Also the highly general dual cost functions used by Berndt and Khaled (1979) are not used because they require factor cost data for cities that is not presently available. The production functions found in Table 1 are of the traditional type and have dominated the studies in this area.

The actual statistical procedure follows the 'exhaustive' testing method utilized by Mizon (1977), with some modification. It is essentially

Table 1

Functional Forms Tested ${ }^{a}$

\begin{tabular}{|c|c|}
\hline (1) Cobb-Douglas (A,M) & $Q=A K^{\alpha} L^{\beta}$ \\
\hline (2) Cobb-Douglas, trans. (A,M) & $Q / L=A(K / L)^{\alpha} L^{\gamma}$ \\
\hline (3) CES (M) & $Q=A\left(\delta K^{-\rho}+(1-\delta) L^{-p}\right) \cdots / \rho$ \\
\hline (4) CES, trans. (A,M) & $\mathrm{Q} / \mathrm{L}=\mathrm{AL}^{\gamma}\left(\delta+(1-\delta) \frac{\mathrm{K}}{\mathrm{L}}-\infty\right)-\mu / \rho$ \\
\hline (5) Kmenta CES (M) & $\ln \frac{\mathrm{Q}}{\mathrm{L}}=\alpha_{0}+\alpha_{1} \ln \mathrm{L}+\alpha_{8} \ln \frac{\mathrm{K}}{\mathrm{L}}+\alpha_{3}\left(\ln \frac{\mathrm{K}}{\mathrm{L}}\right)_{2}$ \\
\hline (6) ACMS CES (A,M) & $\mathrm{Q} / \mathrm{L}=\mathrm{AW}^{\circ}$ \\
\hline (7) Arrow CES (A,M) & $\mathrm{Q} / \mathrm{L}=\mathrm{AW} \cdot \mathbf{Q}(\lambda(1-\bullet))$ \\
\hline (8) Mukerji VES (A,M) & $Q=A\left(\delta K^{-\infty 1}+(1-\delta) L^{-\infty 2}\right)^{-\mu / \rho s}$ \\
\hline (9) Revankar VES (M) & $Q=A K^{\alpha\left(1-s_{\rho}\right)}(L+(p-1) K)^{\alpha s_{\rho}}$ \\
\hline (10) Vinod (A,M) & $\ln Q=\alpha_{0}+\alpha_{1} \ln \mathrm{K}+\alpha_{2} \ln \mathrm{L}+\alpha_{3} \ln \mathrm{K} \ln \mathrm{L}$ \\
\hline (11) Translog (M) & $\ln Q=\alpha_{0}+\alpha_{1} \ln K+\alpha_{2} \ln \mathrm{L}+\alpha_{3} \ln \mathrm{K} \ln \mathrm{L}+\alpha_{\triangleleft}(\ln \mathrm{K})^{2}+\alpha_{s}(\ln \mathrm{L})^{2}$ \\
\hline (12) Ringstad (M) & $\ln Q+\gamma(\ln Q)^{2}+\Theta Q=A\left(\frac{K}{L}\right)^{\circ} L^{\prime \prime}$ \\
\hline
\end{tabular}


a three step process which uses a) tests for nested functions, b) relative fit tests for nonnested functions and c) an absolute measure of fit, Akaike's test. Each of these tests are discussed next.

\section{Nested Tests}

The term 'exhaustive' used by Mizon refers to the fact that the models in Table 1 are first arranged into as many nested groups of functions as possible. ${ }^{1}$ The implicit parameter restrictions in each nest are then tested using standard $F$ and $\chi^{2}$ tests. Insignificant test values indicate acceptance of the more restricted model. For example, referring to Table 1 , two 'nested' functions would be the ACMS $\left(\mathrm{Q} / \mathrm{L}=\mathrm{AW}^{\sigma}\right)$ and the Arrow $(\mathrm{Q} / \mathrm{L}=$ $A W^{\sigma} Q^{\lambda(1-\sigma)}$ forms of the CES. If the implied restriction in the ACMS function $(\lambda=0)$ is rejected with a significant $F$ or $\chi^{2}$ value, then the Arrow function is to be accepted over the ACMS. If the F and $\chi^{2}$ tests do not agree then both functions are accepted.

For the sake of completeness and in order to develop a hierarchical ranking of preferred functions, models rejected by the nested tests are subsequently included in the non-nested tests, though not in the final absolute test. There are two obvious reasons researchers may be interested in a hierarchical ordering: a rejected model may possess desirable economic properties useful in theoretical research, or a production function that is statistically less preferable may be computationally more tractable, especially in a large simultaneous equation system.

\section{Non-nested tests}

For each set of two non-nested models there is initially no 'more general' model. In this case the recently developed tests of Pesaran and Deaton (PD) and Davidson and MacKinnon (DM) are suitable for model discrimination provided that the functions have the same dependent variable. Each of the tests requires the temporary establishment of one model as the null hypothesis $\left(\mathrm{H}_{0}\right)$ and the other as the alternative hypothesis $\left(\mathrm{H}_{1}\right)$. After performing the appropriate test and deciding to accept or reject $\mathrm{H}_{0}$, the roles (i.e., $\mathrm{H}_{0}$ or $\mathrm{H}_{1}$ ) of the two models are switched, and the test is conducted again. Although it is possible that the two tests may validate the same model, it is also possible that neither model is preferred, because the two tests accepted different models.

The Pesaran and Deaton test (1978) has its origin in the "Tests of Separate Families of Hypotheses" put forth by Cox (1961). The complete derivation of their statistic can be found in Pesaran and Deaton's study, in which they applied Cox's test to alternative models having several possible nonlinear equations. Given two non-nested, single-equation, possible nonlinear models $\mathrm{H}_{0}$ and $\mathrm{H}_{1}$ :

$$
\begin{aligned}
& \text { (1.1) } \mathrm{H}_{0}: \mathrm{y}=\mathrm{f}\left(\Theta_{0}, \mathrm{X}\right)+\mu_{0} \text {, and } \\
& \text { (1.2) } \mathrm{H}_{1}: \mathrm{y}=\mathrm{g}\left(\Theta_{1}, \mathrm{Z}\right)+\mu_{1},
\end{aligned}
$$

in which $\mu_{\mathrm{i}}(\mathrm{i}=0,1)$ is normally distributed with variance $\sigma_{\mathrm{i}}^{2}, \mathrm{f}$ and $\mathrm{g}$ are independent of $\mu_{\mathrm{i}}$, and plim $\theta_{i}=\theta_{i}(i=0,1)$, the test statistic $T_{0}$ is expressed:

$$
\text { (1.3) } \mathrm{T}_{0}=\frac{\mathrm{T}}{2}\left(\ln \left(\hat{\sigma}_{1}^{2} / \hat{\sigma}_{10}^{2}\right)\right),
$$

where the maximum likelihood estimated variances are:

$$
\begin{aligned}
& \text { (1.4) } \hat{\sigma}_{1}^{2}=\frac{1}{T}\left(y-f\left(\hat{\sigma}_{0}\right)\right)^{\mathrm{I}}\left(\mathrm{y}-\mathrm{f}\left(\Theta_{0}\right)\right), \\
& \text { (1.5) } \hat{\sigma}_{1}^{2}=\frac{1}{\mathrm{~T}}\left(\mathrm{y}-\mathrm{g}\left(\hat{\theta}_{1}\right)\right)^{\mathrm{I}}\left(\mathrm{y}-\mathrm{g}\left(\hat{\theta}_{1}\right)\right), \\
& \text { (1.6) } \hat{\sigma}_{10}^{2}=\hat{\sigma}_{0}^{2}+\hat{\sigma}_{\alpha}^{2} \text {, and } \\
& \text { (1.7) } \hat{\sigma}_{\alpha}^{2}=\frac{1}{\mathrm{~T}}\left(\mathrm{f}\left(\hat{\theta}_{0}\right)-\mathrm{g}\left(\hat{\theta}_{10}\right)\right)^{\mathrm{I}}\left(\mathrm{f}\left(\hat{\theta}_{0}\right)-\mathrm{g}\left(\hat{\theta}_{10}\right)\right) .
\end{aligned}
$$

The predicted values $\mathbf{g}\left(\hat{\Theta}_{10}\right)$ are obtained by estimating (1.2) using the predicted values from (1.1) as the dependent variable. The formulation of $\mathrm{T}_{0}$ allows for an interaction between $\mathrm{H}_{0}$ and $\mathrm{H}_{1}$ such that the relative performance of the models is measured. The variance of $\mathrm{T}_{0}$ is given by:

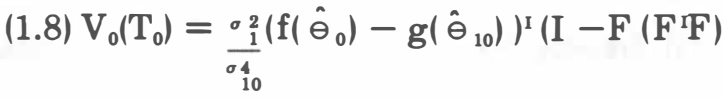

$$
\begin{aligned}
& \left.F^{I}\right)\left(f\left(\hat{\theta}_{0}\right)-\mathbf{g}\left(\hat{\theta}_{10}\right),\right.
\end{aligned}
$$

where $\hat{\mathrm{F}}$ is the Jacobian matrix of $\mathrm{H}_{0}$, i.e. $\hat{\mathrm{F}}=\partial$ $f\left(\theta_{0}\right) / \partial \theta_{0}$, evaluated at $\theta_{0}=\hat{\theta}$. The test is 
then performed by comparing

$$
\text { (1.9) } \mathrm{N}_{0}=\mathrm{T}_{0} / \mathrm{V}_{0}\left(\mathrm{~T}_{0}\right)
$$

to some critical value of student's $t$, using a two-tail test.

The tests developed by DM are closely related conceptually to the $\mathrm{PD}$ test and are simply called the "C-test," "J-test," and "P-test." The test strategy used in this paper and also that suggested by DM begins by applying the "C-test"to all pairs of non-nested models (having the same dependent variable). Given $\mathrm{H}_{0}$ and $\mathrm{H}_{1}$ as above, and the same initial assumptions, the "C-test" involves regressing $\mathrm{Y}$ on the predicted values of $f$ and $g$ :

$$
\text { (2.0) } \mathrm{Y}=(1-\alpha) \hat{\mathrm{f}}+\alpha \hat{\mathrm{g}}+\epsilon \text {. }
$$

The coefficient $\hat{\alpha}$ is then tested for significance using a "t-test." If $\hat{\alpha}$ is significantly different from zero, the null hypothesis is rejected. Since, as shown by DM, the variance of $\hat{\alpha}$ is asymptotically biased upward in the "C-test," there is an increased probability of making a Type II error. Therefore, the test may not reject $\mathrm{H}_{0}$ as often as if the variance of $\hat{\alpha}$ were unbiased. If the "C-test" does not result in an unequivocal conclusion, the next step in their procedure is to use either the "J-test" (2.1) or the "P-test" (2.2):

$$
\begin{aligned}
& \text { (2.1) } \mathrm{Y}=(1-\alpha) \mathrm{f}\left(\theta_{0}, \mathrm{X}\right)+\alpha \hat{\mathrm{g}}+\mu \\
& \text { (2.2) } \mathrm{Y}-\hat{\alpha \hat{f}}=(\hat{\mathrm{g}}-\hat{\mathrm{f}})+\hat{\mathrm{FB}}+\epsilon \text {. }
\end{aligned}
$$

The "J-test" is used when $\mathrm{H}_{0}$ is linear and the "P-test" is used when $\mathrm{H}_{0}$ is nonlinear. (In both cases a significant $\hat{\alpha}$ indicates that $\mathrm{H}_{0}$ is rejected). The PD test, which does not have linearity restrictions, is also implemented at this stage in an attempt to corroborate the findings of the DM test.

\section{Akaike's Test}

The completion of the nested and non-nested tests results in the elimination of several models considered to be statistically inferior to the remaining ones. Since the previous tests were conducted within each error type and dependent variable category, the models that haven't yet been rejected consist of a heterogeneous set of functional forms with different dependent variables and error types. Since relative fit tests have not been devised that can discriminate among such a diverse group, the final test must be a measure of absolute fit. Akaike's test statistic (1974), first developed by Akaike and subsequently used by both Mizon (1977) and Anselin (1984), takes into account the maximized $\log$-likelihood value $\left(\mathrm{L}_{\mathrm{i}}\right)$ as well as the number of estimated parameters $\left(\mathrm{K}_{\mathrm{i}}\right)$ in each function:

$$
\text { (2.4) } \mathrm{AIC}_{\mathrm{i}}=-2 \mathrm{~L}_{\mathrm{i}}+2 \mathrm{~K}_{\mathrm{i}}
$$

Arranging the functions from lowest AIC to highest AIC would then give the final desired order of urban production functions, from most preferred to least preferred.

\section{Data and Estimation}

The observations consist of a pooled sample of manufacturing sector data for 47 of the largest U.S. SMSAs, $1975-1977^{2}$. A pooled sample is used in order to increase the number of observations to 141 so as to reduce the effect of random variation and multicollinearity. Value added is used as the measure of output, and manhours or wage rates of production workers is used to measure labor inputs, depending on the functional form. Both were obtained from the Census/Survey of Manufacturers.

Capital inputs are measured by capital stock and were obtained from Fogarty and Garofalo (1978). They utilized the "perpetual inventory/ book value" method of estimation, which is outlined as follows: first, a 50 year investment series for the manufacturing sector of each SMSA is derived, called the "built-up" series, for the years 1904-1953. In some cases this was obtained by apportioning a state's investment among SMSAs on the basis of the percentage of value added in the SMSA compared to the state. Discard and depreciation functions were then used to adjust gross investment for obsolescence and depreciation.

Census book values of plants and equipment for 1957 were then used as benchmarks to adjust the build-up investment series. Capital stock in any one year is the sum of the previous years' undiscarded, undepreciated investments. Since the pre-1954 investment series consisted of estimates derived from national data, while the post 1953 series consisted of direct survey data, the 1975-1977 estimates 
Table 2

Production Function Estimates ( $t$-values in parentheses)

\begin{tabular}{|c|c|c|c|}
\hline Function & Error & Estimate & Log-Likelihood \\
\hline Cobb-Douglas & A & $Q=\begin{array}{l}12.0 \mathrm{~K}^{.252} \mathrm{~L} \cdot 139 \\
(78.8)^{\mathrm{b}}(8.5)^{\mathrm{b}}(27.1)^{\mathrm{b}}\end{array}$ & -1192 \\
\hline Cobb-Douglas & $\mathbf{M}$ & $\begin{aligned} Q= & 6.13 K^{380} L^{.054} \\
& (11.4)^{b}(8.2)^{b}(12.7)^{b}\end{aligned}$ & -1163 \\
\hline $\begin{array}{l}\text { Cobb-Douglas, } \\
\text { transformed (CDTR) }\end{array}$ & $\mathbf{A}$ & $\begin{aligned} \frac{\mathrm{Q}}{\mathrm{L}}= & 7.03 \frac{\mathrm{K}}{\mathrm{L}} \cdot .348 \mathrm{~L}^{.040} \\
& (6.9)^{\mathrm{b}}(9.0)^{\mathrm{b}}(2.4)^{\mathrm{b}}\end{aligned}$ & -1176 \\
\hline $\begin{array}{l}\text { Cobb-Douglas, } \\
\text { transformed (CDTR) }\end{array}$ & $\mathbf{M}$ & $\begin{aligned} \frac{Q}{L}= & 6.49 \frac{K}{L} \cdot{ }^{350} L^{.048} \\
& (12.3)^{b}(8.4)^{b}(2.6)^{b}\end{aligned}$ & -1159 \\
\hline Direct CES & $\mathbf{M}$ & $\begin{aligned} Q= & 3.57\left(.733 K^{-.57}+.267 L^{-.57}\right)^{(1.046 /-.572)} \\
& (1.89)^{d}(2.46)^{b}(1.07)(2.46)^{b}(1.07)(59.7)^{b}(1.07)\end{aligned}$ & -1158 \\
\hline $\begin{array}{l}\text { Direct CES } \\
\text { transformed (CESTR) }\end{array}$ & A & $\begin{aligned} \frac{\mathrm{Q}}{\mathrm{L}}= & 3.59 \mathrm{~L}^{.038}\left(.25+.75 \frac{\mathrm{K}}{\mathrm{L}}-. .59\right)^{(1.038 /-.59)} \\
& (1.93)^{\mathrm{d}}(2.14)^{\mathrm{c}(.92)}(.92)(1.26)(2.14)^{\mathrm{c}}(1.26)\end{aligned}$ & -1175 \\
\hline Direct CES & $\mathbf{M}$ & 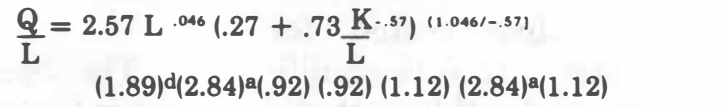 & -1158 \\
\hline Kmenta & $\mathbf{M}$ & $\begin{array}{c}\ln \frac{\mathrm{Q}}{\mathrm{L}}=1.32+.046 \ln \mathrm{L}+7.41 \ln \frac{\mathrm{K}}{\mathrm{L}}-.065\left(\ln \frac{\mathrm{K}}{\mathrm{L}}\right)^{2} \\
(2.5)^{\mathrm{c}}(2.6)^{\mathrm{a}}(2.1)^{\mathrm{c}}(1.1)\end{array}$ & -1158 \\
\hline ACMS & $\mathbf{A}$ & $\begin{array}{l}\frac{Q}{L}=8.07 w^{.571} \\
(5.0)^{b}(5.13)^{b}\end{array}$ & -1194 \\
\hline ACMS & $\mathbf{M}$ & $\begin{array}{l}\frac{Q}{\mathrm{~L}}=7.03 \mathrm{w}^{.645} \\
\quad(10.7)^{\mathrm{b}}(6.22)^{\mathrm{b}}\end{array}$ & -1174 \\
\hline Arrow & $\mathbf{A}$ & $\begin{aligned} \frac{Q}{L}= & 5.33 \mathrm{w}^{.496} \mathrm{Q}^{.135(1-.496)} \\
& (4.5)^{\mathrm{b}}(4.6)^{\mathrm{b}}(3.2)^{\mathrm{a}}(4.6)^{\mathrm{b}}\end{aligned}$ & -1186 \\
\hline Arrow & $\mathbf{M}$ & $\begin{aligned} \frac{\mathrm{Q}}{\mathrm{L}}= & 4.6 \mathrm{w}^{.533} \mathrm{Q}^{.16|(1-.553)|} \\
& (5.1)^{\mathrm{b}(5.6)^{\mathrm{b}}(3.5)^{\mathrm{a}}(5.6)^{\mathrm{b}}}\end{aligned}$ & -1164 \\
\hline Mukerji & A & $\begin{aligned} Q= & .502\left(.63 \mathrm{~K}^{-.4}+.37 \mathrm{~L}^{-.15}\right)(1.571-.28) \\
& (.45)(6.2)^{\mathrm{b}}(5.3)^{\mathrm{b}}(6.2)^{\mathrm{b}}(3.9)^{\mathrm{b}}(.73)(.67)\end{aligned}$ & -1192 \\
\hline Mukerji & $\mathbf{M}$ & $\begin{aligned} Q= & \left.1.0015\left(.87 K^{-.59}+.13 L^{-.136}\right)^{(1.88} /-.33\right\} \\
& (2.2)^{\mathrm{d}}(41.6)^{\mathrm{b}}(20.9)^{\mathrm{b}}(41.6)^{\mathrm{b}}(7.9)^{\mathrm{b}}(5.7)^{\mathrm{b}}(13.3)^{\mathrm{b}}\end{aligned}$ & -1156 \\
\hline Revankar & $\mathbf{M}$ & $\begin{aligned} Q= & 5.24 K^{1.045}(1-(.56)(9.993) \\
& \frac{(4.7)^{\mathrm{b}}(56)^{\mathrm{b}}(7.0)^{\mathrm{a}}(230)^{\mathrm{a}}}{(\mathrm{L}-.007 \mathrm{~K})^{(1.045)(.56)(.993)}} \\
& (230)^{\mathrm{a}}(56)^{\mathrm{b}}(7.0)^{\mathrm{a}}(230)^{\mathrm{a}}\end{aligned}$ & -1158 \\
\hline Vinod & $\mathbf{A}$ & $\begin{array}{c}\ln Q=2.42+.26 \ln K+.75 \ln L-.0013 \ln K \ln L \\
(2.7)^{a}(2.5)^{c}(4.6)^{c}(.074)\end{array}$ & -1192 \\
\hline Vinod & $\mathbf{M}$ & $\begin{array}{c}\ln Q=-.886+.70 \ln K+1.22 \ln L-.065 \ln K \ln L \\
(.99)(6.3)^{\mathrm{a}}(6.44)^{\mathrm{a}}(3.1)^{\mathrm{a}}\end{array}$ & -1158 \\
\hline Ringstad & $\mathbf{M}$ & $\begin{array}{c}\ln Q+.000022 Q-.022(\ln Q)= \\
2.07+.796 \ln L+.251 \ln \frac{K}{L} \\
(18.9)^{b}(62.0)^{b}(8.15)^{b}\end{array}$ & -1153 \\
\hline Translog & $\mathbf{M}$ & $\begin{aligned} \ln Q= & -1.89+.71 \ln \mathrm{L}+1.29 \ln \mathrm{K}+.044 \ln \mathrm{K} \ln \mathrm{L} \\
& \frac{(-1.4)(1.6)(2.4)^{\mathrm{c}}(.37)}{-.073(\ln \mathrm{K})^{2}-.034(\ln \mathrm{L})^{2}} \\
& (1.18)(-.52)\end{aligned}$ & -1153 \\
\hline
\end{tabular}


used in this study are presumably the least biased of Fogarty and Garofalo's 1957-1977 capital stock series.

No attempt was made to incorporate capacity utilization rates into the capital stock variable. One study, by Lovell, demonstrated that failure to adjust for capacity utilization does not necessarily seriously bias the parameter estimates in a production function. It is possible however, that there may be a slight serial correlation bias due to the choice of years; 1975 was a slack year, with real GNP decreasing by 1.2 percent, while GNP increased in 1976 and 1977 by 5.4 percent and 5.5 percent, respectively. Thus it is likely that part of the increase in production registered in 1976 and 1977 came from a higher capacity utilization rate. Although this may inflict uncertain bias on the estimated returns to scale, it does not affect the results of this study. The focus here is not on specific parameter estimates but on determining an appropriate functional form.

Estimates for each of the functional forms listed in Table 1 are reported in Table 2. Linear or nonlinear least squares were used depending on the functional form. In the latter case the QuasiNewton algorithm was used by the SHAZAM programming language. Although both multiplicative and additive errors were attempted with each function, the additive form was found to be inestimable in several cases. As a result, Table 2 contains only seven additive error forms, compared to 12 multiplicative error forms. Each of the functions having a multiplicative error was first logarithmically transformed prior to estimation. For purposes of comparison they are reported in Table 2 without the transformation.

\section{Results}

\section{Relative Tests-Additive Error}

The results for the additive error case are shown diagramatically in Figure 1 . In the $Q / L$ dependent variable category, the CESTR and ACMS functions were rejected in favor of the CDTR and Arrow functions. The non-nested test between the CDTR and Arrow functions did not produce a clear favorite, and so both must be retained for the absolute fit tests. In the case of the dependent variable $Q$, the Vinod and Mukerji functions were each rejected in nested tests with the CD function. Although the Vinod was preferred over the Mukerji in the non-nested tests, both functions are eliminated from final consideration because of the results of the nested tests.

Figure 1

Additive Error Results

Dependent Variable Q/L

Dependent Variable Q
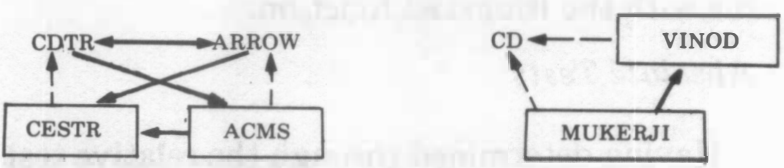

NOTE: $\mathrm{A} \rightarrow \mathrm{B}$ indicates that $\mathrm{B}$ was preferred over $\mathbf{A}$. A dotted line stands for a nested test and a solid line indicates a non-nested test. Lines having double arrows show that the test was inconclusive. Functions that are boxed were eliminated from final consideration by the nested model tests.

Figure 2

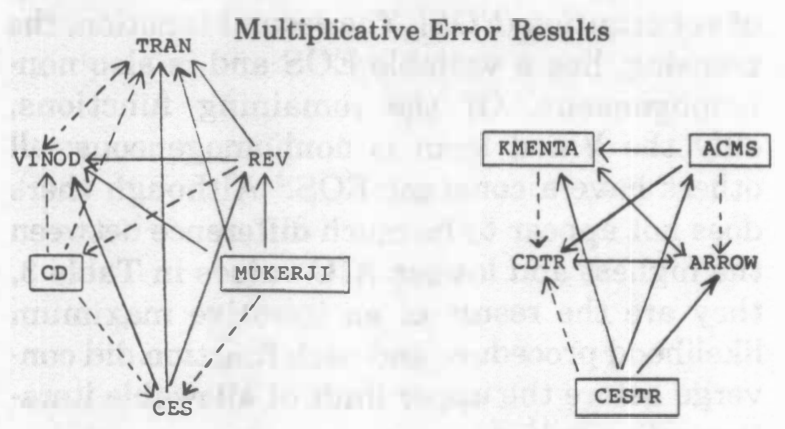

Relative Tests-Multiplicative Error

Figure 2 summarizes the results for the multiplicative error case. In the $\ln Q / L$ dependent variable category, the three functions eliminated by the nested tests are the Kmenta, ACMS, and CESTR functions. Non-nested tests between the two remaining functions, the Arrow and the CDTR, did not produce a clear favorite-just as in the additive error case. Both functions must therefore be retained for the absolute fit tests.

In the $\ln \mathbf{Q}$ category the Cobb-Douglas and the Mukerji functions were both eliminated in favor of the CES function. The CES was then rejected in all three of its non-nested tests. Among the remaining three functions the Revankar (REV) form was rejected by both the translog and the Vinod functions. In the nested test between the latter two, neither function was preferred. 
Finally, another function having a multiplicative error, but which does not fit into either the $\ln Q$ or $\ln Q / L$ categories, is the Ringstad function. Although it has a unique dependent variable (with parameters on the left side of the equation) it can be tested against the multiplicative error Cobb-Douglas (CD) using nested tests. The results indicate rejection of the CD in favor of the Ringstad function by both the $F$ and $\chi^{2}$ tests. No other relative tests are possible with the Ringstad function.

\section{Absolute Tests}

Having determined through the relative test procedure a set of preferred production functions, the final discriminating criterion to be applied is the absolute test of Akaike. The AIC values of the eight functions which "survived" the relative tests are listed in Table 3. The most preferred function (having the lowest AIC value) is the Ringstad function, which is nonhomogeneous and has a unitary elasticity of substitution (EOS). The second function, the translog, has a variable EOS and is also nonhomogeneous. Of the remaining functions, only the Vinod form is nonhomogeneous; all others have a constant EOS. ${ }^{3}$ Although there does not appear to be much difference between the highest and lowest AIC values in Table 3, they are the result of an iterative maximum likelihood procedure and each function did converge before the upper limit of allowable iteration was reached.

Table 3

AIC Values of Most Preferred Urban Production Functions

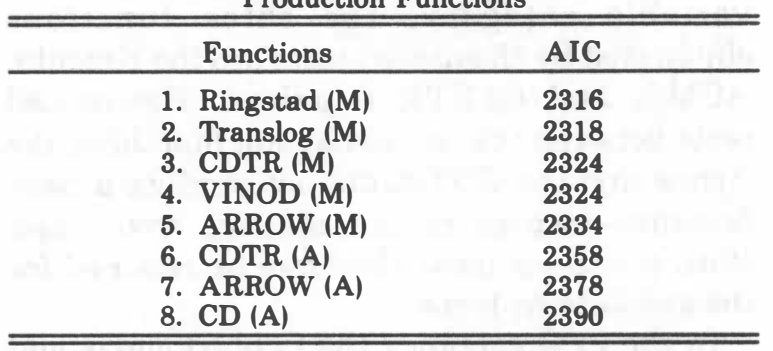

The error types are given in parentheses, i.e., $\mathbf{M}=$ multiplicative, $\mathbf{A}=$ additive.

\section{Conclusion}

The purpose of determining an optimum set of urban production functions is to eliminate some of the guesswork involved in urban model building. An empirical approach requir- ing extensive statistical testing was used in this study since there was no a priori theoretical basis for preferring any one functional form over another. The alternate method of justifying a particular functional form on strictly theoretical grounds would be difficult, if not impossible. The statistical, empirical approach seems to be the only sensible path to take.

If a production function has been accepted empirically then it would be preferable to use that function in building a theoretical model. Since the two most preferred functions, the Ringstad and the translog, have the property of being nonhomogeneous, it suggests that the constant scale economies assumption used in many urban studies is not a very realistic one. Of course it is recognized that the assumption is frequently used in order to reduce the scale of a model and thus make it more easily solvable. It also appears that flexibility in the specification of EOS is not a necessary element of the urban production function. That is, there is no discernible pattern in the EOS properties of the functions listed in Table 3.

Finally, it is of course possible that these results may be 'data specific.' To affirm this would require a repeat of the estimation and hypothesis testing procedure using a different data base. In particular it would be instructive to experiment with different years, levels of aggregation, and size range of cities to see if the results are consistent. Although this would be a laborious process, it would in many ways enhance both theoretical and empirical research in this area if the true urban production function could be determined with more certainty.

\section{FOOTNOTES}

\footnotetext{
'Two models are nested if a limiting process applied to the more general model's parameters reduces it to the same functional form as the less general model.

${ }^{2}$ A complete list of the SMSAs used will be furnished on request.

'Although the Vinod form is often called a VES function, the functional form of its EOS usually does not allow variation of more than 1 percent-not enough to warrant the label VES.
}

\section{REFERENCES}

Akaike, H. "A New Look at the Statistical Model Identification," IEEE Transactions on Automatic Controh 19, 1974, 761-723.

Alperovich, Gershon. "Scale Economics and Diseconomics in the Determination of City Size Distribution," Jour 
nal of Urban Economics, 12, 1982, 202-213.

Anselin, Luc. "Specification Tests and Model Selection for Aggregate Spatial Interaction: An Empirical Comparison," Journal of Regional Science, Vol 24, No. 1, 1984, 1-15.

Arrow, K. J. "The Economics of Implication of Learning by Doing," Review of Economic Studies, 29, 1962, 155-173.

H. B. Chenery, B. Minhas, and R. M. Solow. "Capital-Labor Substitution and Economic Efficiency," Review of Economics and Statistics, 43, 1961, 225-250.

Berndt, Ernst R. and Mohammed S. Khaled. "Parametric Productivity Measurement and Choice Among Flexible Functional Forms," Journal of Political Economy, Vol. 87, No. 6, 1979, 1220-1245.

Christensen, L. R., D. W. Jorgenson, and L. J. Lau. "Transcendental Logarithmic Production Function Frontiers," Review of Economics and Statistics, 55, 1973, 23-27.

Cox, D. R. "Tests of Separate Families of Hypotheses" in Proceedings of the Fourth Berkeley Symposium on Mathematical Statistics and Probability, Vol. 1. Berkeley: University of California Press, 1961.

Davidson, R. and J. G. MacKinnon. "Several Tests for Model Specification in the Presence of Alternative Hypotheses," Econometrica, 49, 1981, 781-793.

Dragonette, Joseph E. "Return to Scale: Some TimeSeries Evidence," Eastern Economic Journal, Vol. 9, No. 1, Jan/March 1983, 23-28.

Fogarty, M. S. and G. A. Garofalo. "An Exploration of the Real Productivity Effects of Cities," Review of Regional Studies, Vol. 8, No. 1, 1978, 65-82. "Capital Stock Estimates for Metropolitan Areas, 1957-1977," paper presented at the Pittsburgh Simulation and Modeling Conference, 1982.

Goldstein, G. S. and T. J. Gronberg. "Economics of Scope and Economics of Agglomeration," Journal of Urban Economics, 16, 1984, 91-104.

Garofalo, G. A. and M. S. Fogarty. "A Note on the Measurement of Agglomeration Economies with Compensation for Urban Disamenities," Journal of Environmental Economics and Management, 10, 1983, 383-387.
Henderson, J. V. "The Sizes and Types of Cities," American Economic Review, 64, 1974, 640-656.

Hoover, E. M. The Location of Economic Activity, New York: McGraw Hill, 1948.

Isard, W. Location and Space Economy. Cambridge, MA: The MIT Press, 1956.

Kmenta, J. "On Estimation of the CES Production Function," International Economic Review, 8, 1967, 180-189.

Lande, Paul S. "The Interregional Comparison of Production Functions," Regional Science and Urban Economics 8, 1978, 339-353.

Leech, D. "Testing the Error Specification of Nonlinear Regression," Econometrica, 43, 1975, 719-725.

Lovell, C. A. K. "Capacity Utilization and Production Function Estimation in Postwar American Manufacturing," Quarterly Journal of Economics, 82, 1968, 219-239.

Mizon, G. E. "Inferential Procedures in Nonlinear Models: An Application in a UK Industrial Cross-Section Study of Factor Substitution and Returns to Scale," Econometrica, 45, 1977, 1221-1242.

Mukerji, V. "Generalized SMAC Function with Constant Ratios of Elasticities of Substitution," Review of Economic Studies, 30, 1963, 233-236.

Nicholson, N. "Differences in Industrial Production Efficiency Between Urban and Rural Markets, Urban Studies, 15, 1978, 91-95.

Pesaran, M. H. and A. S. Deaton. "Testing Non-nested Nonlinear Regression Models," Econometrica, 46, 1978, 677-694.

Revankar, N. S. "A Class of Variable Elasticity of Substitution Production Functions," Econometrica, 39, 1971, 61-71.

Richardson, H. W. Regional Growth Theory, New York: Halsted Press, 1973.

Ringstad, V. "Some Empirical Evidence on the Decreasing Scale Elasticity," Econometrica, 42, 1974, 87-101.

Vinod, H. D. "Interregional Comparison of Production Structures," Journal of Regional Science, 13, No. 2, 1973, 261-267.

Yezer, Anthony M. J., and Robert S. Goldfarb. "An Indirect Test of Efficient City Sizes," Journal of Urban Economics, 5, 1978, 46-65. 